\title{
Bulgarian and Russian Zoomorphic Figurative Comparisons Reflecting Human Appearance
}

\author{
Radostina Stoyanova \\ University of Economics \\ Varna, Bulgaria \\ radostina_stoyanova@mail.ru
}

\begin{abstract}
The paper presents the research aimed at the identification of the similarities and differences in zoomorphic figurative comparisons existing to describe human appearance in the Bulgarian and Russian linguocultures. The research is based on the materials of lexicographic publications of $B$. Yanev ${ }^{1}$, K. Ankova-Nicheva ${ }^{2}$, K. Nicheva, S. SpasovaMikhailova and K. Cholakova ${ }^{3}$, A. K. Koshelev and M. A. Leonidova $^{4}$, L. A. Lebedeva ${ }^{5}$, V. M. Mokiyenko ${ }^{6}$, V. M. Ogoltsevv ${ }^{7}$ and R. Holandi ${ }^{8}$.
\end{abstract}

Keywords-zoomorphic figurative comparisons; Bulgarian and Russian linguocultures; interlingual structural-semantic equivalents

\section{INTRODUCTION}

Perceptions by the Bulgarians' and the Russians of the world and their mindset are translated into the linguistic units through their image content. A figurative comparison offers one of the perfect figurative linguistic means, revealing the national consciousness.
B. Yanev, Figurative comparisons with anthropocentric nature in the Bulgarian and English languages (research and dictionary). Plovdiv: "Paisius of Hilendar" University Press, 2013, 370 p

${ }^{2}$ K. Ankova-Nicheva, New phraseological dictionary in Bulgarian, Sophia: "Sveti Kliment Okhridski" University Press, 1993, 462 p.

${ }^{3}$ Phraseological dictionary in Bulgarian, vol. 1, A - N. / Contr. K. Nicheva, S. Spasova-Mikhailova, Kr. Cholakova. Sophia: Bulgarian Academy of Sciences publication, 1974, Vol. I,760 p.

Phraseological dictionary in Bulgarian, vol. 2. O - Ya. / Contr. K. Nicheva,

S. Spasova-Mikhailova, Kr. Cholakova. Sophia: Bulgarian Academy of Sciences publication, 1975, Vol. II. 780 p.

${ }^{4}$ A. K. Koshelev, Bulgarian-Russian phraseological dictionary / Contr. A.

K. Koshelev, M. A. Leonidova - M.: Russian Language; Sophia: Science and Art, 1974, $635 \mathrm{p}$.

${ }^{5}$ L. A. Lebedeva, Sustained comparisons of the Russian language: thematic dictionary / L. A. Lebedeva, Second edition, M.: FLINTA: Science, 2015, $316 \mathrm{p}$.

6 V. M. Mokienko, The Great Dictionary of Russian folk comparisons / V. M. Mokienko, T. G. Nikitina; edited by V. M. Mokienko. M.: ZAO "OLMA Media Group", 2008, 800 p.

7 V. M. Ogoltsev, Dictionary of sustained comparisons of Russian (synonymous -antonymic), M.: OOO "Russian Dictionaries": Astrel Publishing: AST Publishing House, 2001, 800 p.

8 R. Holandi, Sustained comparisons: Russian, Bulgarian, English, German, French. - Blagoevgrad: South-West University Press "Neofit Rilski”, 2008. 472 p.
The figurative comparisons form the essential part of actively used units in the Bulgarian and the Russian languages.

Images of animals represent the better part of images that a person associates with an idea of one's appearance. People had been living with animals from the earliest times, for centuries fixing in mind qualities, character, habits and behaviour of the latter: a swine usually means a stout person (Bulg. debel kato svinya - Rus. big (fat) as a swine), a cat has a quiet, stealthy and subtle pace (Bulg. st'pva kato kotka - Rus. a cat-like pace), a giraffe is tall (Bulg. visok kato giraf - Rus. tall like giraffe) and so on. These earmarks are passed down through the generations and fix in memory of people belonging to the same linguoculture and, so comprise their general knowledge. Such earmarks are evoking specific associations that give birth to the figurative comparisons. The figurative comparisons of the native speakers of different languages are similar in some ways and in some ways differ in the result of natural, cultural, historical and other factors

\section{SEMANTIC Structure OF ZOOLEXEMES}

Zoolexemes feature a divergent semantic structure with several characteristic components. At its basis lies the 'denotation', carrying a 'presentational' meaning (in our case this is a definite animal): the fox - a predatory mammal of the family Canidae, the cat-a predatory mammal of the cat family.

A person perceives any animal according to its specific characters (the fox - an animal with distinctive sharp face and long bushy tail); however, domestic animals have also a certain functional use in household the swine - an artiodactyl mammal, the domestic species of which are bred for pork, bacon, skin). The summation of these features in the semantic structure of zoolexemes introduces another component, called 'significate' of an animal's relevant name.

To denote the features of an animal, attributed to it by a man, the linguistics applies the term 'connotata' (or connotation, connotative meaning, additional meaning). The evaluativity and expressivity constitute the basic parameters of connotative meanings: A swine, about a man demeaning himself, acting meanly, crudely'. 


\section{THE MOdEL OF Figurative COMPARISONS}

Figurative comparisons have a tripartite model as follows:

- Subject of thought (the compared object - a man);

- Basis of comparison (a feature common for a man and an animal);

- Standard (image) of comparison (an animal as carrier of the trait).

Between the basis of comparison (feature) and the standard (image) of comparison there is a 'comparative form word' (the preposition of comparison kato ${ }^{9}$, less often - kato che li, syakash (kato da), comp. Russ. conjunction like, less often - as, as if) that turns the comparison into language fact. The Russian language also has conjunctionless comparisons, wherein a noun is featured in the instrumental case: Russ. head/who has/egg-like (head/who has/like an egg); Rus. to have a look/ to look/ hawk (to have a look/ to look/ like hawk).

\section{STRUCTURAL TYPES OF ZOOMORPHIC BULGARIAN AND RUSSIAN FIGURATIVE COMPARISONS EXPRESSING HUMAN APPEARANCE}

The first part (the basis of the comparison) of the figurative zoomorphic comparison can be expressed by a verb, an adjective or a noun. As examples, we place some typical examples.

- The zoomorphic figurative comparisons with the first component, expressed by a verb: Bulg. opuliam ochi kato varen zaek (dial.); Bulg. vonia kato prch; Bulg. smrdya kato por; Russ. to have a look (to look) like an owl, goggle-eyed (disappr.); Russ. smells like a goat; Russ. to glare as a lynx (poet.)

- The zoomorphic figurative comparisons with the first component, expressed by an adjective: Bulg. slab (tnk, sukh) kato glist-Russ. skinny (lean) as a belly worm.

There are examples where the first part of the Bulgarian and Russian figurative comparisons, describing human appearance, are expressed variably by a verb or an adjective. Comp. Bulg. cherven (pochervenyavam, zachervya se, izchervyavam se) kato <varen> rak, etc.; Rus. red (to red) as a <boiled> lobster (about one's complexion); Rus. black (to turn black) as a crow - Bulg. cheren kato garvan etc.

- The zoomorphic figurative comparisons with the first component, expressed by a noun: Bulg. Vezhdi kato piyavtsy - Russ. 'brows like leech', 'curved eyebrows'; comp. Russ. eyebrows /one's/ like fawns (pet form, dial. appr.); Bulg. ochi kato na bivol Russ. lit. bull-like eyes; Bulg. ochi kato na zhaba Russ. lit. frog-like eyes; Rus. snout as of a pig (vulg. colloq.); Rus. a monkey-like face - Bulg. grozen kato maimuna; Rus. mare's legs (dial.); Rus. horse-like thighs (dial.); Russ. child like a froglet (belit.derogat.).

\footnotetext{
9 In Bulgarian linguistics, the form word ' $k a t o$ ' inside a comparative phrase acts as a preposition.
}

In Russian the figurative comparisons, reflecting human appearance, the second part can be presented by a noun in the subjective case (Rus. black as a rook; shorn-sighted as an owl (dial., disapr.); sheep (lamb)-like crispy, (curly, frizzed) or in the objective case with a preposition (for example, in the genitive case with the proposition 'of': Rus eyes/who's/ as of a wolf; eyes as of a rabbit; eyes as of (like) an owl; eyes as of a horse; eyes as of a hawk (falcon); eyes as of an eagle; eyes as of a lynx; eyes of a sheep; eyes as of an ox; eyes as of a goat; eyes of a cow; eyes as of a cat; eyes as of a female cat; eyes as of a fallow deer; eyes as of an eagle; eyes as of a fish; eyes of a predator).

\section{TYPES OF BULGARIAN AND RUSSIAN ZOOMORPHIC FIGURATIVE COMPARISONS, EXPRESSING HUMAN APPEARANCE, IN TERMS OF MORPHOLOGICAL STRUCTURE}

Regarding the standard (image) of comparison as the morphological structure there are the following types:

A. A monolexemic image (Bulg. roshav kato garga; Rus. curly as sheep)

\section{B. A bilexemic image}

1) With one pre position attribute (Bulg. krven kato popova svinya; Rus. skinny as a shabby cat; Rus. eyes as of a mad cow; Rus. face <spotted in color> as a bird's egg / colloq., hum., ir./);/);

2) With one post position attribute (Bulg. hubav kato prase v pumia; izskhnal kato zmiya na trn; Rus. beautiful as a grey mare (folk, ir.); Rus. sits like a saddle on a cow).

\section{A multilexemic image}

1) With two pre position attributes (Bulg. slab/slaba kato tnkovrata byals gska);

2) With two and more post position attributes (Bulg. slab (tnk) kato che sa go machki tsitsali; gol kato oskubana kokoshka na pokaz v kasapnitsa; Rus. have a look (look) as an owl, goggle-eyed /disapr./);/)

3) With pre preposition and post position attributes (Bulg. Stpvam kato podkovano magare na led; Rus. hardman as two eggs in a saucepan) [1].

\section{STEREOTYPE IMAGES IN THE BULGARIAN AND RUSSIAN LINGUOCULTURES}

In minds of people of the same linguocultures, the stereotype images emerge as a reflection of the most outstanding qualities, featuring the appearance of animals, insects, birds and fish. Consequently, the figurative comparisons identify the specifics of zoomorphic pattern of different ethnic groups' culture, the identity of their linguistic world image.

The choice of the standard (image) of the comparison depends on the everyday and cultural experience of members of such linguoculture. For this very reason, associations with some features or other in different languages may be at variance.

The following can be referred to the figurative comparisons, reflecting a person appearance in the Bulgarian 
and the Russian linguocultures: a pig - stout, dirty (Bulg. debel kato svinya (prase, shopar) - Rus. stout (fat) as a pig); a giraffe - tall (Bulg. visok kato jiraf - Rus. tall as a giraffe), a roach - dry (Bulg. slab (mrshav, sukh) kato chiroz - Rus. dry (dried out) as a roach); a cow - fat (Bulg. debel/debela kato krava - Rus. fat as a cow).

These are established figurative comparisons, used by native speakers for an extended period of time. In this, they differ from the individual-author comparisons (Rus. clean as a piglet (dial., ind-auth., hum.) 'about a super clean, rosyskin, cared-for man'; Rus. stick out as ears of a leveret (ind. -auth., hum.) 'about sticking up lapels of a coat'.

We have identified the Bulgarian and Russian alogical zoomorphic figurative comparisons, reflecting human appearance. They are characterized by verve, expressivity: Bulg. tnk (mrshav) kato svinya (ir.) - Rus. lit. 'thin, skinny as a pig ${ }^{, 10}$, stout (fat) as a pig); Bulg. hubav kato prase $v$ pumia (ir.) - Rus. lit. 'handsome as a pig in hog-wash', 'by no means handsome, Bulg. krasiva kato drta maimuna - Rus. lit. 'handsome as an old monkey', 'by no means handsome; Bulg. krasiv kato ameba - Rus. lit. handsome as an amoeba', 'by no means handsome'; Bulg. krasiv kato gushcher-Rus. lit. 'handsome as a lizard', 'by no means handsome'; Bulg. krasiv kato nastpan chervey - Rus. lit. 'handsome as a crushed worm', 'by no means handsome'; Bulg. krasiv kato trup na kon - Rus. lit. 'handsome as a dead horse', 'by no means handsome'; Bulg. nisk kato giraf - Rus. lit. 'short as a giraffe', 'tall'; Bulg. debel kato payak na dieta - Rus. lit. 'stout as a spider on a diet', 'skinny'.

\section{TYPES OF INTERLINGUAL STRUCTURAL-SEMANTIC EQUIVALENTS OF THE BULGARIAN AND RUSSIAN ZOOMORPHIC FIGURATIVE COMPARISONS, EXPRESSING HUMAN APPEARANCE}

In the figurative comparisons of the Bulgarian and Russian languages, in which find the reflection both universal notions of a person about certain animals (comp.: Bulg. slab (tnk, sukh) kato glist - Rus. skinny (lean) as a belly worm, their attributes and qualities, associations that are common only for a certain ethno-lingual worldview (comp. Bulg. zhlt kato papuniak 'about complexion', Rus. hairstyle like a crow's nest; Rus. hat like a crow's nest; Rus. as if cow-chewed (colloq. ironic), about very wrinkled clothes' [2].

In the seen Bulgarian and Russian zoomorphic figurative comparisons, expressing human appearance, the following interlingual structure-semantic equivalents are revealed:

\section{A. Complete interlingual structural-semantic equivalents of the zoomorphic figurative comparisons}

Bulg. vrat kato na bik - Rus. bull neck; Bulg. cherven kato 〈varen> rak - red as <boiled> lobster; Bulg. cheren kato garvan - Rus. black as a crow; Rus. black as a bug; Bulg. khodya kato mokra kokoshka - Rus. wanders as a bedraggled hen (scornf.).

\footnotetext{
${ }^{10}$ If there is no translation equivalent of the Bulgarian or Russian figurative comparison, Russian or Bulgarian interpretation is given in French quotes $<$ >.
}

The availability of complete interlingual structuralsemantic equivalents of the zoomorphic figurative comparisons arises from the similarity of the perception and re-thinking of the realities by Bulgarians and Russians.

\section{B. Partial interlingual structural-semantic equivalents of the zoomorphic figurative comparisons}

Bulg. prilicha mi kato na svinya sedlo (dial., ironic) Rus. to sit like a saddle on a cow; Bulg. gledam kato tele pred grmotevitsa - Rus. stare (protrude) like a stag <at a ceiling >.

The similarity in the perception of the world and rethinking by carriers of the Bulgarian and Russian linguocultures become apparent at a more generalized underlying level of the semantics with a partial overlapping of the plan of expression of the zoomorphic figurative comparisons.

For instance, the Bulgarian lexeme svin'ya and Russian svin'ia are intended to describe a big, fat and chubby man: Bulg. debel kato svin'ya - Rus. fat (stout) as (like) a pig (svin'ia); Bulg. tnk kato svin'ya (iron.), Bulg. ugoyen kato dunavska svin'ya; Bulg. krven kato popova svin'ya. In addition, the Bulgarians also associate a stout man with a piglet (Bulg. debel kato prase), a hog (Bulg. debel kato shopar; naklal se kato shopar), a bull (Bulg. pylen kato bik, Bulg. naklal se kato bik), a whale (Bulg. debel kato kit), an elephant (Bulg. debel kato slon), a hippo (Bulg. debel kato hipopotam), a seal (Bulg. debel kato tyulen), a cow (Bulg. debel kato krava) and a rooster (Bulg. debel kato nadut petel).

The standards of comparison describing a stout, fat and chubby man in the Russian figurative comparisons include a swine (Rus. fat (stout) as (like) a swine; Rus. to batten /grow plump/ as (like) a swine), a young pig (Rus. fat (big) as a young pig), a boar (Rus. plump like a boar), a hog (Rus. plump/ fat/ like a hog; Rus. podgy as a young hog), a hippo (Rus. big (clumsy) like a hippo; a cow (Rus. stout (big) like a cow (disapr.), Rus. to fatten like a cow (dial., disapr.), Rus. to grow fat as a milch cow (disapr.), Rus. to develop a pouch as a cow), an elephant (Rus. huge (stodgy, husky, a great hulk) like an elephant), a cat (Rus. he looks like a cat (disapr.) 'about a paunched person gazing with oily eyes') and a bear cub (Rus. big like a bear cub / about a child/).

The dissimilarities in the lexical context do not disrupt the semantic equivalence of the zoomorphic figurative comparisons. Comp.: Bulg. byal kato gska 'about a person with frosty hair' - Rus. lit. 'grey as a goose', white-snow.

The dissimilarities in the image-evaluation system of human appearance in the Russian and Bulgarian linguocultures are often marked when the figurative comparison is being expanded. Comp.: Bulg. ugoyen kato dunavska svin'ya - Rus. lit. 'chubby as a Danube swine'. 
C. The zoomorphic figurative comparisons without semantic parallelism in the comparable linguoculturesBulg. klepnali mu ushite kato na drta svin'ya - Rus. lit. hanging down ears as of old pig's; Bulg. sin kato puicha glava (dial.), 'very blue, turned blue with cold' - Rus. lit. blue as a turkey's head; Bul. vezhdi kato $<$ morski> piyavitsi, 'curved eyebrows' - Rus. lit. eyebrows like <sea> leeches; Rus. to walk like booted chicken (dial., iron.), about people wearing boots with long and fluttering stripes'; Rus. as if licked by a cow (dial., disapr.) 'about a dirt, greasy stain on clothes'; Rus. grey like a toad (disapr.) 'about a person with a sallow complexion; Rus. red as kalist ${ }^{11}$ (dial.) 'about a beet-faced, sanguine and excessively stout person', red eyes as of rabbit's, 'about man's eyes red because of eyestrain, insomnia, crying, alcohol abuse or disease', etc.

These examples mirror the experience and cogitation pattern of just one social medium, marking the culture-bound features of this nation.

\section{THE DELIVERY OF HUMAN APPEARANCE CHARACTERISTICS BY THE BULGARIAN AND RUSSIAN ZOOMORPHIC FIGURATIVE COMPARISONS}

Comparing the characteristics presented in the Bulgarian and Russian zoomorphic figurative comparisons, it is noteworthy that the Russian language presents more widely the figurative comparisons reflecting minutest observations of the state of human eyes, hair, skin and complexion and describing tiniest visual features. Comp. Rus. grey as a toad (disapr.), face <spotted in colour> like a bird's egg (colloq., hum., ir.), face like a crow's egg (colloq., hum.); a horse face, face like horse's, face like snout; like cat's green (yellow) eyes; eagle eye (vision); glint in the eyes like those of a cat; glare like a lynx (poet.), yellow lynx-like eyes, wolf-like eyes; red eyes like rabbit's; eyes as of (like) owl; big eyes like cow's; round eyes like bird's; round eyes as of owl (eagle owl, hawk); eyes like mad cow's (slang, dial.), etc.

Our analysis of the zoomorphic figurative comparisons has identified that in the Bulgarian and Russian linguocultures dominate the figurative comparisons that mark negative features of a person's appearance (such as fatness, an excessive leanness, meagreness, pale face, sickly look, weakness, inharmonious or stained clothes and such), while the figurative comparisons representing the positive features of appearance (such as beauty, nice manner of walking, slenderness, etc.) are less common. This can be explained by the fact that in any linguoculture there is a unique scale "reflecting the publicly established norms of vision of good or bad, or the manifestations of above or below normal" [3]. The positive zoomorphic naming units, expressing a man's appearance, introducing the common conventions, generally do not require additional figurative marking.

\section{CONCLUSION}

The associative bonds between the appearance of a man and an animal bases on people's observation, comprehending different aspects of human appearance.

The comparative analysis of the zoomorphic figurative comparisons applied when describing human appearance in the Bulgarian and Russian linguocultures made it possible to identify three main types of their relations:

- Full equivalence (match of the tertium comparationis with the standards (images) in the comparable languages);

- Similarity of the tertium comparationis with the variance of chosen standard images;

- Dissimilarity of the tertium comparationis of the corresponding standard of comparison.

Comp. Bulg. grozen kato bulldog; Bulg. grozen kato gligan; Bulg. grozen kato maimuna; Bulg. grozen kato orangutan; Bulg. grozen kato gorilla; Bulg. grozen kato por; Bulg. grozen kato zhaba; Bulg. grozen kato svraka; Bulg. Grozna kato kukumyavka; grozna kato krokodil; Bulg. hubav kato prase v pumia (iron.); Bulg. krasiv kato gushcher 'ill-looking'; Bulg. krasiv kato nast'pan chervei 'ugly'; Bulg. krsiv kato ameba 'ugly'; Comp. Bulg. grozen kato bulldog; Bulg. grozen kato gligan; Bulg. grozen kato maimuna; Bulg. grozen kato orangutan; Bulg. grozen kato gorilla; Bulg. grozen kato por; Bulg. grozen kato zhaba; Bulg. grozen kato svraka; Bulg. grozna kato kukumyavka; grozna kato krokodil; Bulg. hubav kato prase v pumia (ir.); Bulg. krasiv kato gushcher 'ill-looking'; Bulg. krasiv kato nast'pan chervei 'ugly'; Rus. a child like a frogling (belit.-derogat., or hum.) 'about an ugly-looking with long hands and legs, looking helpless child'; Rus. pretty as a grey horse (folk, iron.) 'about an ill-looking, ugly and (often) older woman.

In our examples, the similarities and variations are shown both in the selection of features underlying the comparison and in the selection of the standard of comparison, which illustrates different perception of the world in the Bulgarian and Russian linguocultures.

\section{REFERENCES}

[1] B. Yanev, Figurative comparisons with anthropocentric nature in the Bulgarian and English languages, (research and dictionary), Plovdiv: University Press "Paisius of Hilendar", 2013, pp. 46-47.

[2] R. Stoyanova, Zoomorphic Cultural Codes in the Semantics of Bulgarian and Russian Similes, ASSEHR: Advances in Social Science, Education and Humanities Research, Paris: Atlantis Press, 2017, pp. 520-525.

[3] V. N. Telia, Connotative aspect of nominal units' semantics. Moscow: Nauka, 1986, p. 39.

\footnotetext{
${ }^{11}$ kalist (dial.) - stork
} 